\title{
Coulisses
}

Revue de théâtre

14 | Printemps 1996

Varia

\section{Création : Urbs par le TUFC}

\section{(2) OpenEdition}

1 Journals

Édition électronique

URL : http://journals.openedition.org/coulisses/4797

DOI : $10.4000 /$ coulisses. 4797

ISSN : 2546-9460

\section{Éditeur}

Presses universitaires de Franche-Comté

\section{Édition imprimée}

Date de publication : 1 mai 1996

Pagination : 70

ISSN : 1150-594X

\section{Référence électronique}

«Création: Urbs par le TUFC », Coulisses [En ligne], 14 | Printemps 1996, mis en ligne le 20 mars 2019, consulté le 27 octobre 2019. URL : http://journals.openedition.org/coulisses/4797 ; DOI : 10.4000/ coulisses.4797

Ce document a été généré automatiquement le 27 octobre 2019.

Coulisses 


\section{Création : Urbs par le TUFC}

\section{Création collective du théâtre universitaire de Franche-Comté sur le thème de la ville}

Animateur-metteur en scène : Joseph Melcore.

La ville? C'est quoi?

La ville? C'est une histoire, c'est un rythme, c'est un mouvement.

La ville? C'est l'histoire, une histoire, celle de chacun de ses habitants qui se croisent, se rencontrent, se voient, s'abordent, s'ignorent.

La ville ? C'est l'histoire qui se construit, de la survie à l'opulence, du petit groupe à la foule.

La ville? C'est un parcours, celui du piéton, celui du cycliste, de l'automobiliste, celui des panneaux vert, bleu, rouge, permis, défendu, sens giratoire, interdit de stationner, sens interdit.

La ville? Ça monte, ça descend, avec des escaliers, des escalators, des ascenseurs, poussifs ou véloces.

La ville? C'est des bruits, des odeurs, des couleurs. Marteaux-piqueurs, freinages, marchés, transpirations, choses et couleurs des hommes.

C'est le petit vacancier à la campagne qui demande un enregistrement des bruits familiers pour se retrouver.

La ville? C'est le travail de tous : implantation, émergence, érection, pour se défendre, se protéger, se retrouver, vivre. C'est le groupe qui s'élargit sans fin, s'agglutine, fasciné par son effort même.

La ville? Au détour d'une rue, c'est la pénombre, la flaque, celui qui crève les pneus, qui incendie, qui se prostitue.

La ville ? C'est la fête, la beauté, les lumières, l'utopie.

La ville? C'est Babel, sans cesse recommencée.

\section{Pourquoi la ville?}

2 Depuis sa création, les membres du Théâtre Universitaire de Franche-Comté, étudiants de toutes disciplines, désireux de «faire du théâtre » travaillent sous la direction de Joseph Melcore, à des créations collectives sur le monde d'aujourd'hui, tel qu'ils le perçoivent. La trentaine d'étudiants qui forment le groupe acquièrent, peu à peu, les moyens propres à l'art théâtral, pour exprimer, moins par le discours que par le corps 
tout entier, un point de vue à la fois personnel et collectif. Porteurs de l'histoire de notre temps, ils donnent à voir la complexité de notre univers contradictoire, déchiré mais aussi passionnant. Par exemple, l'ordre du monde ou son désordre, a été évoqué sous forme de remémoration historique dans Trajectoires en 1989, sous celle de songerie à la fois épique et lyrique dans Corps. Dans cette perspective, la ville séduisante et destructrice avait de quoi nous attirer.

Un des objectifs du Théâtre Universitaire est de mettre en relation les deux pôles de la recherche, théorique et pratique. Trajectoires, Guanikana ont été crées en relation avec des colloques universitaires en l'honneur du bicentenaire de la Révolution Française et de la découverte de l'Amérique. La représentation donnait ainsi un contenu concret à des considérations abstraites. Or, le C.R.E.H.U., Centre de recherches sur l'espace humain et urbain nous a proposé de participer à leur prochain colloque international, et de rendre compte de notre expérience. C'est pourquoi, le thème de travail retenu a été celui de la ville.

Le spectacle s'élabore à partir d'improvisations, de documents théâtraux ou non apportés par chaque participant et d'exposés-débats de différents spécialistes. Comme il est perpétuellement en train de se faire, le résultat final reste toujours un étonnement $\mathrm{Au}$ spectateur de dire s'il retrouve dans les images d'un monde familier transmuté, une réalité transformable.

\section{BIBLIOGRAPHIE}

B. BRECHT,

Baal, Ed. de L'Arche

Dans la jungle des ville, Ibid.

Grandeur et décadence de la ville de Mahogany

BIBLE : Sodome et Gomorrhe, Babel

Upton SINCLAIR,

Lajungle

Les poètes expressionnistes allemands

Emile VERHAEREN, Les villes tentaculaires, Le livre de poche

Les voies de la création théâtrale : La ville

THÉÂTRE DU SOLEIL, L'âge d'or, Texte programme, Théâtre Ouvert, Stock.

Les Cahiers du C.R.E.H.U., particulièrement les $n^{\circ} \mathrm{s}: 2,3,4,5,6$ 